\title{
AL-QUR'AN DAN APLIKASI TEKNOLOGI MIKROHIDRO DI INDONESIA
}

\author{
Erry Ika Rhofita \\ Fakultas Sains dan Teknologi, UIN Sunan Ampel Surabaya \\ Email : erryikarhofita@ rocketmail.com
}

\begin{abstract}
ABSTRAK
Agama Islam mengajarkan kepada ummatnya selalu menjaga kelestarian alam yang diterangkan dalam beberapa ayat dalam Al-Qur'an. Salah satu cara untuk menjaga kelestarian alam melalui aplikasi teknologi mikrohidro sebagai energi alternatif terbarukan (renewable energy) yang ramah lingkungan sesuai dengan ajaran Islam. Konsep dasar dalam aplikasi teknologi mikrohidro adalah debit air dalam bentuk aliran sungai dan ketinggian (head) secara terperinci dituliskan dalam QS. Ar-Ra'd ayat 17 jauh sebelum turbin ditemukan. Di dalam Al-Qur'an juga telah dijelaskan beberapa ayat yang dapat dijadikan pedoman dalam penerapan mikro hidro sesuai dengan konsep persamaan mikro hidro seperti; daya mekanis mikrohidro, ketinggian air, debit air, dan gravitasi. Makalah ini membahas konsep dasar penerapam mikrohidro yang dibuktikan dan berpedoman pada Al-Qur'an. Dengan demikian, dapat disimpulkan bahwa Al-Qur'an akan selalu menjadi pedoman utama ilmu pengetahuan dan teknologi (iptek), serta petunjuk dan motivasi bagi semua umat manusia dalam setiap aspek kehidupan.
\end{abstract}

Kata kunci : Mikro hidro, Energi ramah lingkungan, Al-Qur'an

\section{PENDAHULUAN}

\section{LATAR BELAKANG}

Al-Qur'an sebagai kitab suci umat Islam merupakan kumpulan bacaan mulia yang berisi berbagai makna kehidupan dan dijadikan sebagai pedoman atau acuan ummat Islam dalam menjalankan kehidupan. Selain sebagai petunjuk untuk menuntun akhlak ummat Islam, Al-Qur'an juga dapat dijadikan sebagai sumber ilmu pengetahuan dan teknologi. Seperti halnya yang dikemukakan oleh Tasmara dalam Qutub (2011), bahwa Al-Qur'an merupakan Kalamullah yang menyeluruh dan menjadi sumber inspirasi ummat Islam dalam setiap lini kehidupan, hal ini ditunjukkan dari klasifikasi isi Al-Quran (Tabel 1).

Tabel 1. Klasifikasi isi Al-Qur'an

\begin{tabular}{lcc}
\hline Klasifikasi Isi Al-Qur'an & $\begin{array}{c}\text { Jumlah } \\
\text { Surat }\end{array}$ & $\begin{array}{c}\text { Prosentas } \\
\text { e (\%) }\end{array}$ \\
\hline Fenomena alam dan materi & 32 & 26.66 \\
Aqidah dan aliran pemikiran & 29 & 24.14 \\
Sosial dan politik & 27 & 22.50 \\
Sejarah dan fislasafat sejarah & 17 & 14.14 \\
Perilaku dan akhlak & 4 & 3.30 \\
Masalah harta & 4 & 3.30 \\
Ibadah dan syiar agama & 2 & 1.70 \\
\hline
\end{tabular}

\section{Sumber :}

Jumlah ayat dalam Al-Qur'an yang mencapai 6,236 ayat, diturunkan kepada Nabi Muhammad SAW selama 23 tahun. Ayat-ayat tersebut tidak mengalami perubahan atau amandemen sedikitpun sejak 14 abad yang lalu hingga saat ini. Ayat-ayat Al-Qur'an didalamnya terdapat keajaiban yang mengungkap berbagai ilmu pengetahuan, misal ilmu hukum, ilmu politik, ilmu ekonomi, dan juga ilmu-ilmu teknik atau teknologi. Menurut Ahimsa, dkk (2012), banyak ayat dalam Al-Qur'an yang menjelaskan ilmu pengetahuan dan teknologi yang berkembang saat ini. Contohnya dalam bidang teknologi, Al-Qur'an mengungkap berbagai fenomena alam yang telah dibuktikan oleh beberapa ilmuwan, yaitu proses pembentukan air (water cycle) 
yang dikenal dengan siklus hidrologi. Siklus hidrologi telah diterangkan dalam QS. Al-Waqiah ayat 68 dan 69 serta QS Ar-Rum ayat 24. Dalam QS. Al-Waqiah ayat 68 dan 69 dijelaskan bahwa air tawar yang berada di bumi berasal dari hujan, yang turun akibat adanya proses evaporasi (penguapan) dan presipitasi (pengendapan). Sedangkan dalam QS Ar-Rum ayat 24 juga menjelaskan tentang pembentukan siklus air melalui hujan yang diturunkan dari langit.

Siklus hidrologi merupakan siklus alami yang berlangsung secara terus-menerus dibumi dan mempunyai manfaat sebagai wash biosfera, water supply, resource life, dan resource energy. Dengan adanya siklus hidrologi tersebut jumlah air yang ada dibumi relatif stabil, tidak bertambah atau berkurang hanya tempatnya dan kualitas air yang berubah. Besarnya prosentase air di bumi sebesar 72 persen, dimana 97 persen berupa air asin dan 3 persen berupa air tawar. Jumlah air yang begitu besar didalamnya terkandung kekuatan yang dapat dimanfaatkan sebagai sumber energi untuk menopang kehidupan manusia, sesuai dengan manfaat dari siklus hidrologi. Energi air atau yang dikenal dengan istilah hydro power, merupakan salah satu energi alternatif terbarukan (renewable energy) yang dapat dijadikan sebagai pengganti energi fosil (non-renewable energy). Pemanfaatan hydro power dapat berupa mikro hidro dalam skala kecil, dengan mengubah energi potensial air menjadi energi mekanis dan energi listrik. Menurut blue print energi tahun 2006, di Indonesia potensi tenaga air secara keseluruhan sebesar 75.67 Gwatt dan baru dimanfaatkan sebesar 4.2 Gwatt (5.55 persen). Sedangkan potensi mikro hidro sebesar $0.45 \mathrm{GWatt}$, dan baru dimanfaatkan sebagai energi alternatif sebesar 0.084 GWatt. Potensi tenaga yang besar ini menjadikan mikrohidro layak untuk di kembangkan dan diaplikasikan di Indonesia. Dari beberapa uraian selanjutnya dalam makalah ini akan dibahas mengenai ayatayat dalam Al-Qur'an yang berhubungan dengan penerapan teknologi mikrohidro di Indonesia.

\section{HASIL DAN PEMBAHASAN}

\section{KONDISI AIR SUNGAI DI INDONESIA}

Seperti halnya pangan, air memegang peranan penting dalam kehidupan manusia, tidak hanya berfungsi untuk minum, keperluan sehari-hari seperti mandi dan mencuci, tetapi air juga digunakan untuk keperluan irigasi pertanian. Air juga dapat dijadikan sebagai salah satu sumber energi alternatif terbarukan (renewable energy) pengganti bahan bakar fosil (non-renewable energy). Mengingat pentingnya air sebagai penopang kehidupan, di seluruh dunia setiap tanggal 22 Maret diperingati sebagai Hari Air Sedunia (World Day for Water). Setiap tahun dalam peringatan Hari Air Sedunia membahas berbagai permasalahan mengenai dampak pemanasan global terhadap kondisi dan kualitas air.

Saat ini kondisi dan kualitas air semakin menurun, seiring dengan peningkatan populasi yang berdampak meningkatnya jumlah pencemaran air, khususnya pencemaran air sungai. Indonesia sebagai negara tropis mempunyai jumlah sungai sebanyak 5,590 sungai, dengan rata-rata debit air di musin kemarau sebesar $1 \mathrm{~m}^{3}$ per detik dan musin penghujan sebesar $1000 \mathrm{~m}^{3}$ per detik. Dari 5,590 sungai yang ada hampir 80 persen kualitas air sungai menggalami penurunan. Data kualitas air sungai di Indonesia pada tahun 2007 sampai tahun 2012 berdasarkan kriteria mutu air Peraturan Pemerintah 82/2001 Kelas II, menggalami penurunan kualitas sebesar 42 persen untuk dari status cemar ringgan menjadi cemar berat, (BPS, 2014). Secara umum pencemaran air sungai dapat dibedakan menjadi dua katagori, yaitu pencemar yang dapat terurai (biodegradable pollutants), seperti kotoran manusia dan pencemar yang tidak dapat terurai (nonbiodegradable pollutants), seperti bahan kimia dan limbah industri. Kedua katagori pencemar air tersebut berdampak terhadap pengurangan oksigen terlarut, peningkatan derajad eutrofikasi, penurunan keanekaragaman biota air, dan penurunan kualitas air. Beberapa hasil penelitian terdahulu menyatakan kualitas air sungai menggalami peningkatan indeks pencemar seperti pada hasil penelitian yang dilakukan oleh Agustiningsih, $d k k$ (2012) yang menyatakan bahwa di sungai Blukar, Kabupaten Kendal telah terjadi peningkatan nilai indeks pencemar sebesar 1.885 dari nilai sebelumnya sebesar 0.49 (tercemar ringan) menjadi 3.28 (tercemar sedang), akibat peningkatan aktifitas pertanian yaitu penggunaan petstisida. Menurut Siahaan, $d k k$ (2011), adanya peningkatan aktifitas manusia yang memanfaatkan air sungai dan membuang limbah ke sungai berakibat pada turunnya kualitas air sungai Cisadane, hanya bagian hulu dan bagian tengah sungai yang airnya dapat dimanfaatkan sebagai air minum, sedangkan untuk bagian hilir kualitas air telah tercemar parah. Penurunan kualitas air sungai secara tidak langsung juga akan berdampak pada penurunan debit air sungai, setiap tahun akibat adanya aktifitas perumahan, pertanian dan industri rata-rata debit air sungan menggalami penurunan sebesar 38 persen, dan penurunan kualitas air dari indeks tercemar ringan menjadi indeks tercemar berat. Untuk mengurangi besarnya pencemaran sungai di Indonesia diperlukan upaya konservasi air, yang diatur dalam UU RI no. 37 tahun 2014 tentang konservasi air dan tanah. Selain konservasi air, konsistensi manusia dalam menjaga kelestarian alam sangat diperlukan untuk mengurangi pencemaran air sungai. Di dalam Al-Qur'an surat Ar-Rum ayat 41 dan 42, Allah SWT memerintahkan 
kepada manusia untuk selalu menjaga kelestarian lingkungan, agar sistem kehidupan dapat berjalan secara seimbang.

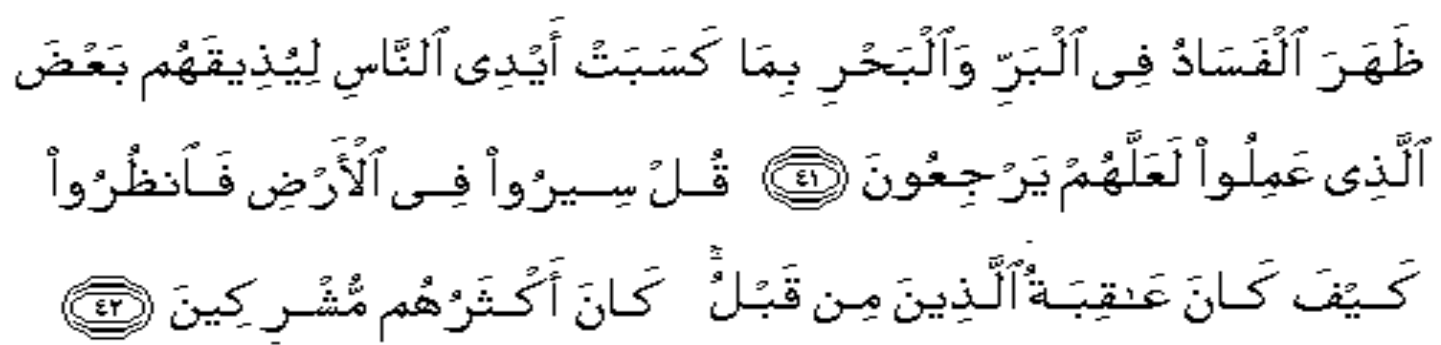

Adapun arti dari QS. Ar-Rum ayat 41 dan 42 adalah sebagai berikut:

"Telah nampak kerusakan di darat dan di laut disebabkan karena perbuatan tangan manusia, supaya Allah merasakan kepada mereka sebagian dari (akibat) perbuatan mereka, agar mereka kembali (ke jalan yang benar), (41). Katakanlah: "Adakanlah perjalanan di muka bumi dan perhatikanlah bagaimana kesudahan orang-orang yang terdahulu. kebanyakan dari mereka itu adalah orang-orang yang mempersekutukan (Allah), (42)."

Dalam tafsir Al-Misbah Volume 10 bahwa dalam QS Ar-Rum ayat 41 dan 42, Allah SWT telah menciptakan alam raya (baik daratan maupun lautan) dalam suatu sistem yang serasi dan seimbang sesuai dengan kehidupan manusia. Apabila dalam melakukan suatu kegiatan manusia bersikap buruk dengan merusak alam, maka akan terjadi ketidakseimbangan dalam sistem kerja alam. Semakin banyak perusakan terhadap lingkungan, semakin besar pula dampak buruknya terhadap manusia. Dan semakin besar pula dosa manusia, semakin besar pula kerusakan alam yang terjadi. Hal tersebut juga diperkuat dalam QS. Al-A'raf ayat 96, yang menjelaskan bahwa alam raya dengan segala bagiannya, saling berkaitan satu sama lainnya dan saling mempengaruhi. Apabila salah satu bagian tidak berfungsi dengan baik dan sesuai dengan ketentuannya, akan berdampak negatif pada bagian yang lainnya, dan pada akhirnya akan mempengaruhi seluruh bagian. Secara tersirat, makna dari QS Ar-Rum ayat 41 dan 42 adalah peringatan agar manusia selalu menjalankan perintah Allah SWT dan percaya hukum alam yang telah ditetapkan oleh Allah SWT tidak mengalami perubahan.

\section{TEKNOLOGI MIKROHIDRO}

Tenaga air (hydro power) klasifikasi hydro power dapat dilihat pada Gambar 1 berikut.

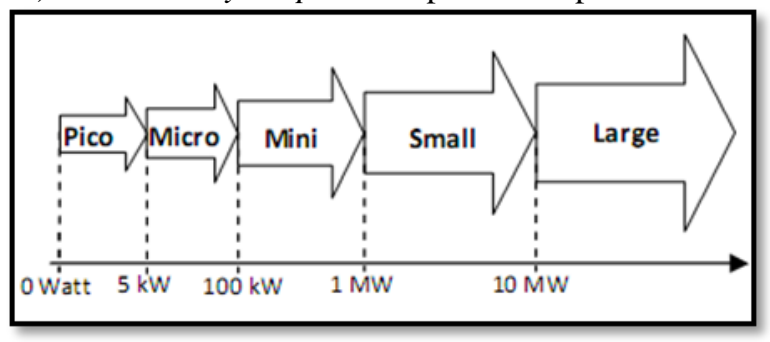

Gambar 1: Klasifikasi hydro power

Mikro hidro merupakan sumber energi alternatif yang berasal dari aliran air yang mampu menghasilkan daya sebesar 5 kWatt sampai $100 \mathrm{kWatt}$, (Basar, et al, 2010). Teknologi mikrohidro dapat diterapkan secara luas di Indonesia dengan beberapa alasan, antara lain: (1) konstruksinya sederhana, (2) mudah dioperasikan, dan (3) mudah dalam perawatan dan penyediaan suku cadang. Ditinjau dari segi ekonomi, penerapan mikrohidro lebih menguntungkan jika dibandingkan teknologi lainnya seperti nuklir maupun tenaga uap, karena biaya investasi dan biaya operasional serta perawatan teknologi mikrohidro lebih rendah jika dibandingkan dengan teknologi lainnya. Secara sosial, teknologi mikrohidro lebih dapat diterima oleh masyarakat secara luas dan sesuai dengan kondisi lingkungan sosial masyarakat Indonesia pada umumnya, sehingga penerapannya dapat tersebar secara luas di Indonesia. Hal tersebut diperkuat oleh pernyataan Basuki dalam Gunawan (2010), teknologi mikro hidro sebagai pembangkit listrik walaupun dalam skala kecil mempunyai beberapa kelebihan, antara lain: (l) energi yang tersedia tidak akan habis selagi siklus dapat dijaga dengan baik, seperti daerah tangkapan atau catchmenl area, vegetasi sungai dan sebagainya; (2) proses yang dilakukan mudah dan murah; (3) tidak menimbulkan polutan yang berbahaya; (4) dapat diproduksi di Indonesia, sehingga jika terjadi kerusakan tidak akan sulit untuk mendapatkan sparepart; (5) penerapan mikrohidro sebagai pembangkit listrik secara tidak langsung penataan dan pengelolaan lingkungan tetap seimbang, sehingga tidak akan menimbulkan kerusakan lingkungan seperti banjir, tanah longsor atau erosi, serta (6) mengurangi tingkat konsumsi energi fosil sebagai upaya meminimalisir pemanasan global. 
Prinsip kerja teknologi mikro hidro dengan memanfaatkan beda ketinggian dan jumlah debit air per detik yang ada pada aliran air saluran irigasi, sungai atau air terjun. Aliran air ini akan memutar poros turbin sehingga menghasilkan energi mekanik. Energi mekanik ini selanjutnya digunakan menggerakkan generator dan menghasilkan listrik. Skema teknologi mikro hidro secara terperinci ditunjukkan oleh Gambar 2.

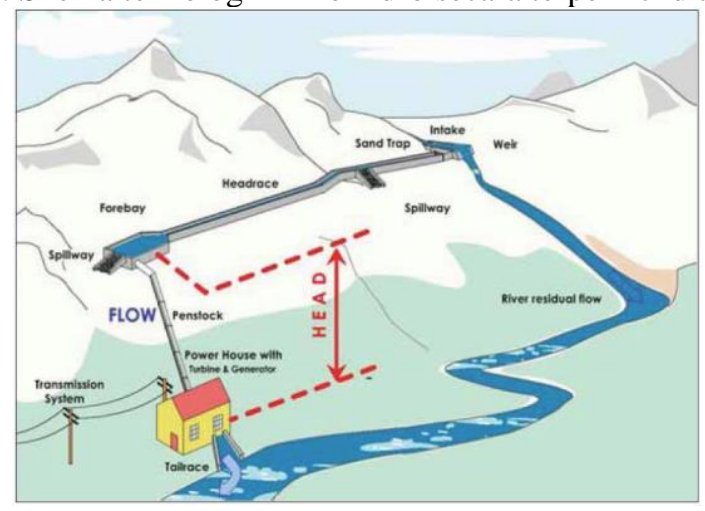

Gambar 2: Skema teknologi mikro hidro

Daya yang tersedia dalam mikrohidro sebanding dengan tekanan dan debit air, yang dapat dinyatakan dalam Persamaan 1, (Paish, 2002).

$$
P=\eta \times p \times g x Q x H
$$

Dimana $\mathrm{P}$ adalah daya yang dihasilkan dari gerak mekanis mikrohidro, $\mathrm{\eta}$ adalah efisiensi hidrolik, $\rho$ adalah densitas air $\left(\mathrm{kg}\right.$ per $\left.\mathrm{m}^{3}\right)$, g adalah kecepatan gravitasi $\left(\mathrm{m}\right.$ per $\left.\mathrm{s}^{2}\right)$, $\mathrm{Q}$ adalah debit air yang melewati mikrohidro $\left(\mathrm{m}^{3}\right.$ per detik) dan $\mathrm{H}$ adalah ketinggian air yang jatuh kedalam mikrohidro. Efisiensi sistem mikrohidro dapat mencapai 60 sampai 80 persen bergantung pada debit air yang melalui mikrohidro dan jenis turbin yang digunakan, seperti yang ditunjukkan oleh Gambar 3.



Gambar 3: Grafik hubungan efisiensi mikrohidro dengan jenis turbin air yang digunakan

Secara umum turbin yang digunakan dalam teknologi mikro hidro dapat diklasifikasikan menjadi dua yaitu impulse turbine dan reaction turbine. Dari kedua klasifikasi umum tersebut turbin mikrhidro juga dapat diklasifikasikan kembali berdasarkan ketinggian dan jumlah air yaitu high head turbine, medium head turbine dan low head turbine, yang ditunjukkan oleh Tabel 2.

Tabel 2. Klasifikasi turbin dalam teknologi mikro hidro

\begin{tabular}{llll}
\hline Tipe Turbin & Klasifikasi $\mathbf{H e a d}$ & & \\
& Tinggi $(>\mathbf{5 0 m})$ & Sedang $\mathbf{( 1 0 - 5 0 m})$ & Rendah $(<\mathbf{1 0 m})$ \\
\hline Impulse & Pelton & Cross flow & Cross flow \\
& Turgo & Turgo & \\
& Multi jet-Pelton & Multi jet-Pelto & \\
Reaction & Francis (spiral case) & Francis (open-flume) \\
& & & Propeller \\
& & Kaplan \\
\hline
\end{tabular}


Teknologi mikro hidro dengan aketinggian dan debit air telah tertulis dalam Al-Qur'an, yang tertuang dalam QS. Ar-Ra'd ayat 17.

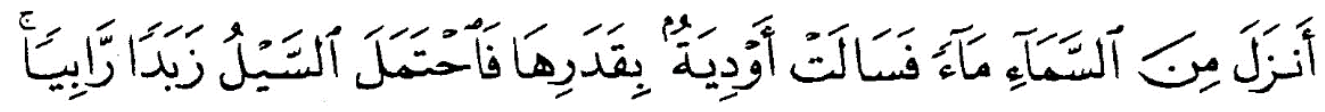

Adapun arti dari QS. Ar-Ra'd ayat 17 adalah sebagai berikut:

"Allah telah menurunkan air (hujan) dari langit, maka mengalirlah air di lembah-lembah menurut ukurannya, maka arus itu membawa buih yang mengambang. "

Dari ayat tersebut, air sebagai sumber energi yang telah dijelaskan sejak 14 abad yang lalu dalam Kalamullah, yang ditunjukkan dalam akhir ayat tersebut seperti yang dijelaskan oleh Quraish Shihab dalam Tafsir Al-Misbah Volume 6 yang menyatakan bahwa air yang diturunkan oleh Allah SWT melalui hujan tidak menjakau semua tempat, tidak pula mengalir di semua lembah, ada lembah yang menampung air dalam jumlah banyak dan ada pula yang tidak dapat menampung air sama sekali. Semua air yang diturunkan oleh Allah SWT mempunyai manfaat bagi kehidupan manusia. Menurut Ibnu Taimiyah dalam Tafsir Ibnu Katsir menjelaskan bahwa air yang turun ke bumi ibarat ilmu pengetahuan. Ilmu pengetahuan yang turun kepada manusia bergantung pada hati manusia itu sendiri, bergantung terhadap kadar keyakinannya. Jika hati manusia mempunyai kadar keyakinan yang tinggi, niscaya akan membawa manfaat kepada kehidupan manusia. Dan jika hati manusia mempunyai keraguan keberkahan ilmu pengetahuan menjadi berkurang. Secara tersirat di dalam QS Ar-Rad ayat 17 mengisyaratkan kepada ummat manusia untuk selalu menjaga keimanan terhadap Allah SWT dan Al-Qur'an sebagai petunjuk dalam menjalankan kehidupan.

\section{PENERAPAN TEKNOLOGI MIKROHIDRO DI INDONESIA}

Penerapan teknologi mikrohidro di Indonesia sudah banyak dilakukan dan sebagai salah satu upaya dalam memecahkan masalah energi dan pemanasan global. Penerapan teknologi mikro hidro di Indonesia dapat dijadikan salah satu syarat program pembangunan sosial ekonomi masyarakat Indonesia secara berkelanjutan, akibat adanya peningkatan pertumbuhan penduduk yang diimbangi dengan peningkatan perekonomian. Penerpan teknologi mikro hidro di Indonesia juga mempunyai potensi yang besar, hal ini ditunjukkan melalui program pemerintah yang tertuang dalam blue print energi. Menurut Perpres No. 5 tahun 2006 tentang Kebijakan Energi Nasional pada tahun 2025 penggunaan tenaga air, termasuk mikro hidro di Indonesia harus mencapai 5 persen, dimana pada tahun 2015 penggunaanya baru terrealisasi sebesar 62 persen dari yang ditergetkan.

Banyak contoh penerapan teknologi mikro hidro di Indonesia, salah satunya di sungai Ongkak Mongondow di desa Muntoi kabupaten Bolaang Mongondow. Dengan menggunakan pembangkit listrik mikrohidro mampu menghasilkan energi listrik selama 1 tahun sebesar 170.829 MWatt jam Besarnya energi listrik tersebut diperoleh dari tinggi jatuh air sebesar 7 meter dan tenaga air sebesar $19.5 \mathrm{kWatt}$, yang akan mengahasilkan daya sebesar $9.5 \mathrm{kWatt}$ pada debit air $0.458 \mathrm{~m}^{3}$ per detik, (Rompas, 2011). Penerapan mikrohidro sebagai pembangkit listrik juga mempunyai tujuan mewujudkan desa mandiri energi serta membantu peningkatan pertumbuhan ekonomi masyrakat. Hasil kajian yang dilakukan oleh Firmansyah, $d k k$ (2015), menyatakan bahwa PLTMH Dompyong yang memanfaatkan aliran sungai Dompyong dengan debit aliran $0.41 \mathrm{~m}^{3}$ per detik dan tinggi jatuh air (head) 20 meter mampu menghasilkan daya terbangkit sebesar 50.76 kWatt. Penerapan mikro hidro di desa Cibunar Kabupaten Tasikmalaya dengan menggunakan turbin Crossflow dengan head 20 meter dan debit air 300 liter per detik mampu menghasilkan daya $30 \mathrm{kWatt}$ untuk memenuhi kebutuhan listrik sebanyak 54 kepala keluarga, (Susatyo dan Subekti, 2009). Penggunaan daya mikro hidro sebesar 2017,5 kWatt mampu mengaliri listrik 5934 pelanggan rumah ata-rata yang digunakan pelanggan sebesar $340 \mathrm{Watt}$, (Suparno, $d k k, 2014$ ). Selain itu, hal yang sama juga dilakukan oleh Suwignyo (2012), menerapkan mikro hidro sebagai pembangkit listrik pada saluran irigasi Sungai Brantas di Sengkaling Malang yang mempunyai debit air rata-rata $1 \mathrm{~m}^{3}$ per detik dan tinggi jatuhan air 15.20 meter, mampu menghasilkan listrik sebesar $100 \mathrm{kWatt}$. Dari tempat yang sama dan hanya berjarak sekitar 800 meter, dengan debit rata-rata $0.90 \mathrm{~m}^{3}$ per detik dan tinggi jatuhan air 12.75 meter, mampu menghasilkan listrik sebesar $82 \mathrm{kWatt}$.

Ditinjau dari segi ekonomi penerapan teknologi mikro hidro di Indonesia layak untuk dikembangkan dan mempunyai keuntungan yang besar. Rata-rata besarnya pay back periode (PBP) selama 15 tahun. Seperti halnya pada penerapan PLTMH Dompyong mempunyai nilai return of investment (ROI sebesar 12.23 persen, (Firmasnyah, $d k k, 2015$ ). Penggunaan mikro hidro sebagai produsen listrik di Lumajang, mempunyai return of investment (ROI) sebesar 0.98 persen, apabila listrik yang dihasilkan dijual dengan harga Rp. 500 
per kWatt jam dengan besar pay back periode (PBP) selama 17.6 tahun, (Faradina, dkk, 2015). Sedangkan penerapan teknologi mikro hidro di PLTMH Wanganaji mempunyai PBP sebesar 11.9 tahun, (Purwanto, 2011).

\section{KAITAN ANTARA AL-QUR’AN DENGAN PENERAPAN TEKNOLOGI MIKROHIDRO}

Ilmu pengetahuan dan teknologi (iptek) tanpa agama dapat menjadi buta, istilah tersebut banyak dikemukakan oleh para ulama. Iptek dan agama merupakan satu keasatuan yang tak bisa dipisahkan, sebagai ummat Islam penjelasan dan pembuktian mengenai iptek telah diterangkan dalam Al-Qur'an sebagai Kalamullah. Iptek juga dapat dijadikan sebagai sarana untuk mengembangkan agama itu sendiri, (Yusoff \& Othman, 2009). Hubungan antara iptek dengan agama juga diperkuat oleh pernyataan Mahadi Ghulsyani, bahwa salah satu ciri yang membedakan agama Islam dengan yang lainnya adalah penekanannya terhadap masalah ilmu (sains), Al-Qur'an dan Al- Hadist dijelaskan anjuran bagi ummat Islam untuk menuntut ilmu dan mengembangkan teknologi dengan tujuan meningkatkan taraf hidup seseorang. Hal tersebut, juga diperkuat di dalam Al-Qur'an QS. Al-Mujadilah ayat 11.



Adapun arti dari QS. Mujadilah ayat 11 adalah sebagai berikut:

"Allah meninggikan beberapa derajat (tingkatan) orang-orang yang beriman diantara kamu dan orang-orang

yang berilmu. Dan Allah Maha Mengetahui apa yang kamu kerjakan”.

Dalam QS. Mujadilah ayat 11 menunjukan bahwa kewajiban menuntut ilmu bukan hanya ilmu agama tetapi ilmu dunia bagi setiap orang beriman. Ilmu yang bermanfaat bagi kehidupan akan mendapatkan balasan surga, karena dengan ilmu yang dimiliki seseorang akan menumbuhkan kesadaran betapa kecilnya manusia dihadapan Allah, sehingga akan tumbuh rasa takut kepada Allah bila melakukan hal-hal yang dilarangNya. Hal tersebut diperkuat dalam Al-Qur'an QS. Al-Fathir ayat 28.

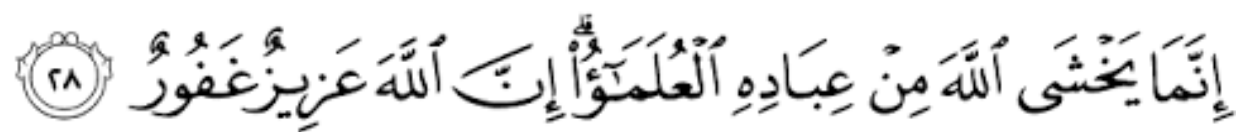

Adapun arti dari QS. Al Fathir ayat 28 adalah sebagai berikut.

"Sesungguhnya yang takut kepada Allah diantara hamba-hambaNya hanyalah ulama (orang berilmu). Sesungguhnya Allah Maha Perkasa lagi maha Pengampun”.

Agama Islam adalah agama terakhir yang diturunkan Allah SWT kepada manusia, dan merupakan petunjuk bagi semua aspek kehidupan termasuk iptek yang berkembang saat ini tertulis dalam Al-Qur'an. Jauh sebelum ipteks berkembang dan dapat dibuktikan secara ilmiah Al-Qur'an telah menjelaskan tentang berbagai iptek dalam bidang teknik, kesehatan, perdagangan maupun humaniora. Salah satunya, Al-Qur'an telah menjelaskan peranan air bagi kehidupan, yang tertuang dalam QS. Ar-Ra'd ayat 17 jauh sebelum teknologi turbin ditemukan pertama kali pada tahun 1700 an oleh Ján Andrej Segner. Dalam QS. Al-Baqarah ayat 164 juga menjelaskan peranan air untuk irigasi yang ditampung dalam sebuah bendungan. Dimana teknologi bendungan telah dibuat oleh negeri Saba' pada 1000 tahun sebelum Nabi Muhammad SAW. Beberapa ayat-ayat dalam Al-Qur'an juga dapat dijadikan pedoman dalam penerapan teknologi mikrohidro sesuai dengan Persamaan 1, yang terdiri daya mekanis mikrohidro, ketinggian air, debit air, dan gravitasi, yang ditunjukkan oleh Tabel 3.

Tabel 3. Ayat dalam Al-Qur'an yang berhubungan dengan penerapan teknologi mikro hidro

\begin{tabular}{|l|l|l|}
\hline Subyek & Surat Al-Qur'an & Ayat \\
\hline Air & ar-Ra'd & 17 \\
\cline { 2 - 3 } & an-Nahl & 65 \\
\cline { 2 - 3 } & al-Anbiya' & 30 \\
\cline { 2 - 3 } & al-Hajj & 63 \\
\cline { 2 - 3 } & ar-Ruum & 48 \\
\hline
\end{tabular}




\begin{tabular}{|l|l|l|}
\hline Subyek & Surat Al-Qur'an & Ayat \\
\hline \multirow{5}{*}{ Sungai } & Qaaf & 9 \\
\cline { 2 - 3 } & al-Qamar & 11 dan 12 \\
\cline { 2 - 3 } & an-Naba' & 14 \\
\hline Ketinggian air & Ibrahim & 32 \\
\cline { 2 - 3 } & an-Nahl & 15 \\
\cline { 2 - 3 } & al-Isra' & 91 \\
\hline & al-Hajj & 63 \\
\hline & al-Mu'minun & 18 \\
\hline & az Zukhruf & 11 \\
\hline & Qaaf & 9 \\
\hline Energi air & an-Naba' & 14 \\
\hline & Abasa & 25 \\
\hline & Al Anbiaya' & 30 \\
\hline & Qaaf & 9 \\
\hline
\end{tabular}

Tabel 3 menunjukkan bahwa Al-Qur'an sebagai Kalamullah harus dijadikan sebagai sumber bagi pengembangan ipteks, khususnya mikro hidro, sehingga dalam pengembangannya tetap menjadikan AlQur'an sebagai dasar pedoman kehidupan. Seperti yang telah diterangkan dalam beberapa ayat dalam AlQur'an tentang konsep mikro hidro, secara sederhana mikro hidro memanfaatkan energi potensial yang dimiliki oleh aliran air pada pada ketinggian (head) tertentu untuk menghasilkan energi mekanik dan energi listrik.

\section{KESIMPULAN}

Al-Qur'an sebagai Kalamullah dapat dijasikan sebagai pedoman, inspirasi, serta bukti kekuasaan Allah dalam pengembangan ilmu pengetahuan dan teknologi (ipteks). Seperti halnya, aplikasi energi air dalam bentuk mikrohidro, yang telah lama dijelaskan dalam Al-Qur'an, salah satunya QS Ar-Rad ayat 17. Dalam Al-Qur'an juga dijelaskan juga mengenai penerapan teknologi mikrohidro dengan konsep dasar pemanfaatan debit air dalam bentuk aliran sungai dan ketinggian (head) untuk menghasilkan energi mekanik dan listrik.

\section{DAFTAR PUSTAKA}

Abbasi, S.A. \& Naseema, A., (2008), Renewable Energy Sources and Their Environmental Impact, New Delhi: PHI Learning Private Limited

Agustiningsih,D., Sasingko, S.B., \& Sudarno, (2012), Prosiding: Analisis kualitas air dan beban pencemaran berdasarkan penggunaan lahan di Sungai Blukar Kabupaten Kendal. Seminar Nasional Pengelolaan Sumberdaya Alam dan Lingkungan, (11 September 2012), 30-37

Ahimsa, Heddy S., \& Putra, (Mei, 2012). Jurnal penelitian: The living Al-Quran: beberapa presfektif antropologi. Jurnal Walisongo 20(1), 235-260

Anjar.S., \& Subekti, R.A., (2009). Prosiding: Implementasi teknologi pembangkit tenaga listrik tenaga mikro hidro kapasitas $30 \mathrm{~kW}$ di Desa Cibunar Kabupaten Tasikmalaya Jawa Barat._Seminar Nasional Daur Bahan Bakar 2009, (13 Oktober 2009), C22-C26

Basar, M.F., \& Rahman, A., (2010), Prosiding: Design and development of green electricity using ocean surface wave. PEA-AIT International Conference on Energy generation system Development: Issues and Strategies (ESD 2010), 1-11

Basar, M.F., Hambali B., \& Kamaruzzaman S., (Juli, 2013), Jurnal Penelitian: Quran as inspiration for implementation of pico hydro system. International Journal of Education and Research 1(7), 1-10

Faradina, W., Suyono, H., \& Utomo, T. (2015). Hasil penelitian: Kajian kelayakan ekonomis pembangkit listrik tenaga mikro hidro Gunung Sawur 1 dan Gunung Sawur 2 di Lumajang. Malang: FT, Universitas Brawijaya

Gunawan, S., Didik E.B., \& Subchan, M. (Desember, 2010). Jurnal Ilmiah: Potensi clean development machanism pada pembangkit mikrohidro $120 \mathrm{~kW}$. Media Elektrika 3 (2), 1-7

Herlambang, A., (2006), Jurnal Penelitian: Pencemaran air dan strategi penanggulangannya, Jurnal Air Indonesia 2 (1), 16-29 
Ifhan, F., Mahmudsyah S., \& Yuwono T., (2015), Artikel Jurnal: Studi pembangunan pembangkit listrik tenaga mikro hidro (PLTMH) Dompyong $50 \mathrm{~kW}$ di Desa Dompyong, Bendungan Trenggalek untuk mewujudkan desa mandiri energi (DME). http://digilib. Its.ac.id/public/ITS-undergraduate-16527-220410116-papar.pdf, (7 Agustus 2016)

Latif, M., \& Ali A., (2012), Jurnal Penelitian: Studi kualitas dan kuantitas air sungai Tallo sebagai sumber air baku. Jurnal Penelitian Jurusan Sipil, Makasar: Universitas Hasanuddin

Paish, O.S., (2002), Article Journal: Hydropower technology and current status. Renewable Sustainable Energy Review 6, 537-556

Purwanto, (Desember, 2011), Jurnal Penelitian: Analisis finansial dan ekonomi pembangkit listrik mikrohidro di berapa lokasi Propinsi Jawa Tengah, Indonesia. Jurnal Penelitian Sosial dan Ekonomi Kehutanan 8(4), 251264

Qutub, S., (Oktober, 2011), Jurnal Ilmiah: Sumber-sumber ilmu pengetahuan dan Al-Qur'an dan Hadits. Jurnal Humaniora 2 (2), 1339-1350

Rompas, Parabelem T.D., (Oktober, 2011), Jurnal Penelitian: Analisis pembangkit listrik tenaga mikrohidro (PLTMH) pada daerah aliran sungai Ongkak Mongondoq di desa Muntoi kabupaten Boolang Mangondow. Jurnal Penelitian Saintek 16 (2), 160-171

SiahaanR., Indrawan, A., Soedharma, D., \& Prasetyo, L.B., (Oktober, 2011), Jurnal Ilmiah: Kualitas air Sungai Cisadane Jawa Barat-Banten. Jurnal Ilmiah Sains 2 (2), Bogor: Institut Pertanian Bogor, 268-273

Suparno., Parsetyawan, Y., \& Rahmadyani, Z. (2014). Prosiding: Pemenuhan kebutuhan listrik di Propinsi Kalimantan Utara. Simposim Nasional RAPI XIII, Surakarta: Universitas Muahammadiyah Surakarta

Tiwari, G.N \& Ghosal, M.K., (2007), Fundamentals of Renewable Energy Sources, United Kigdom: Alpha Science International Ltd, Oxford

Yusoff, M.\& Othman, (2009), Sains Masyarakat dan Agama, Kuala Lumpur: Utusan Publication and Distribution Sd 